This item was submitted to Loughborough's Research Repository by the author.

Items in Figshare are protected by copyright, with all rights reserved, unless otherwise indicated.

\title{
A zero-dimensional combustion model with reduced kinetics for SI engine knock simulation
}

PLEASE CITE THE PUBLISHED VERSION

http://dx.doi.org/10.1080/00102200902864704

PUBLISHER

(c) Taylor \& Francis

VERSION

AM (Accepted Manuscript)

LICENCE

CC BY-NC-ND 4.0

REPOSITORY RECORD

Liu, Zhen, and Rui Chen. 2011. "A Zero-dimensional Combustion Model with Reduced Kinetics for SI Engine Knock Simulation”. figshare. https://hdl.handle.net/2134/8303. 
This item was submitted to Loughborough's Institutional Repository by the author and is made available under the following Creative Commons Licence conditions.

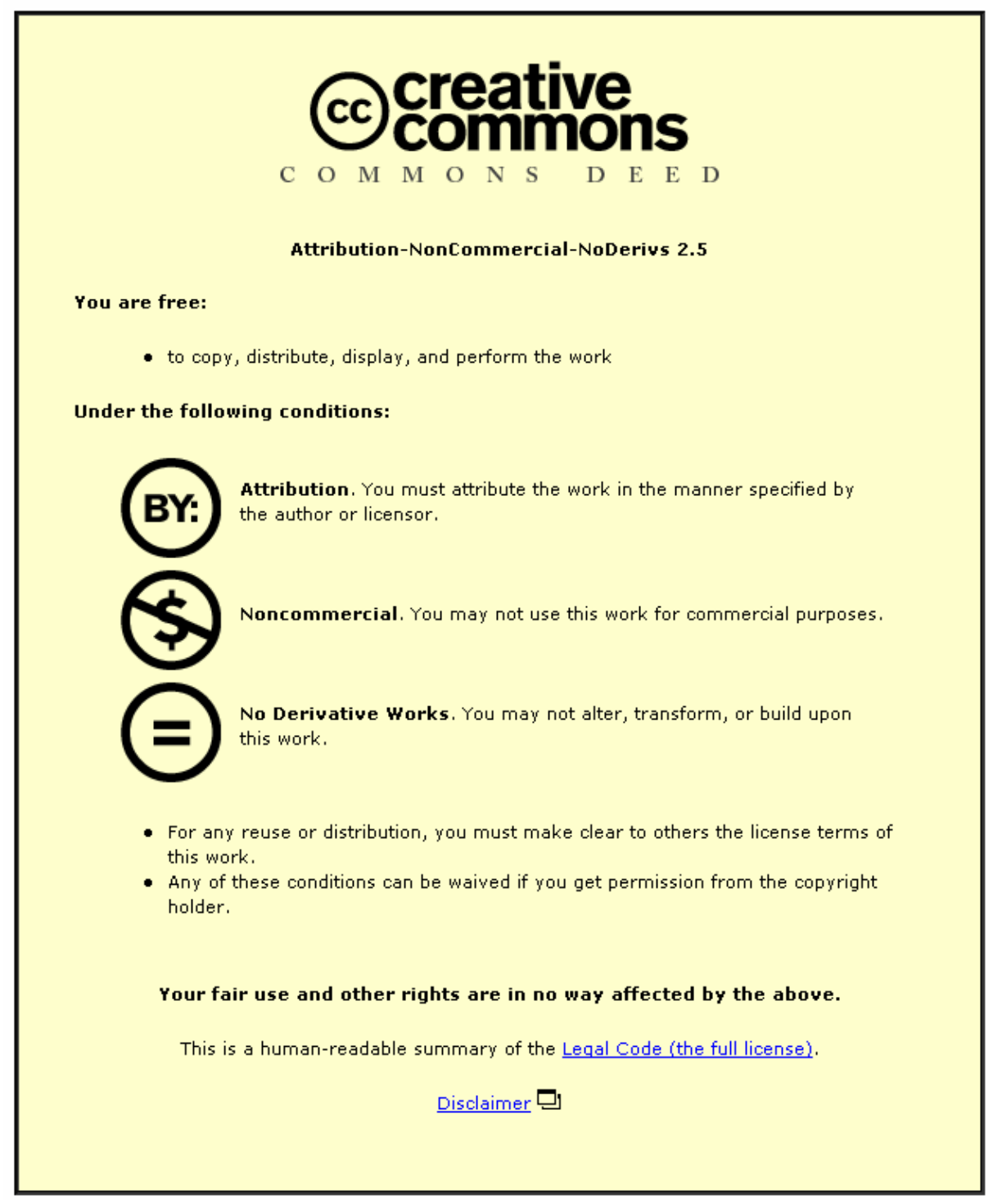

For the full text of this licence, please go to: http://creativecommons.org/licenses/by-nc-nd/2.5/ 
A Zero-Dimensional Combustion Model with Reduced Kinetics for SI Engine Knock Simulation

Zhen Liu, Rui Chen*

Department of Aeronautical and Automotive Engineering, Loughborough University

* Corresponding Author

Department of Aeronautical and Automotive Engineering, Stewart Miller Building, West Park,

Loughborough University, Leicestershire, LE11 3TU, UK

Telephone: $+44(0) 1509227255$

Fax: +44 (0)1509 227275

Email: r.chen@lboro.ac.uk 


\begin{abstract}
High load performance and fuel economy of gasoline engines are limited by knocks. Such limitations are becoming worse when the engine is heavily super-charged for high BMEP outputs. Spark ignition timing retardation has been an efficient method to avoid the knock but results in reduced engine performance and poor fuel economy. A better understanding of knock, which could be used to optimize the engine design, ignition timing optimization in particular, is important. In this research, a simulation model for SI engine knock has been developed. The model is based on a three-zone approach (unburned, burning and burned zones). The Tanaka's reduced chemical kinetic model for a commercial gasoline fuel with an RON of 95 has been modified and applied in both burned and unburned zones incorporated with the LUCKS (Loughborough University Chemical Kinetics Simulation) code. Both post-flame heat release and pre-flame autoignition have be simulated. The burning zone uses equilibrium combustion thermodynamic models. The simulated results have been validated against experimental results, and good agreements have been achieved.
\end{abstract}

\title{
KEYWORDS
}

Spark Ignition, Autoignition, Knock, Chemical Kinetics, Zone Modelling, 


\section{NOMENCLATURE}

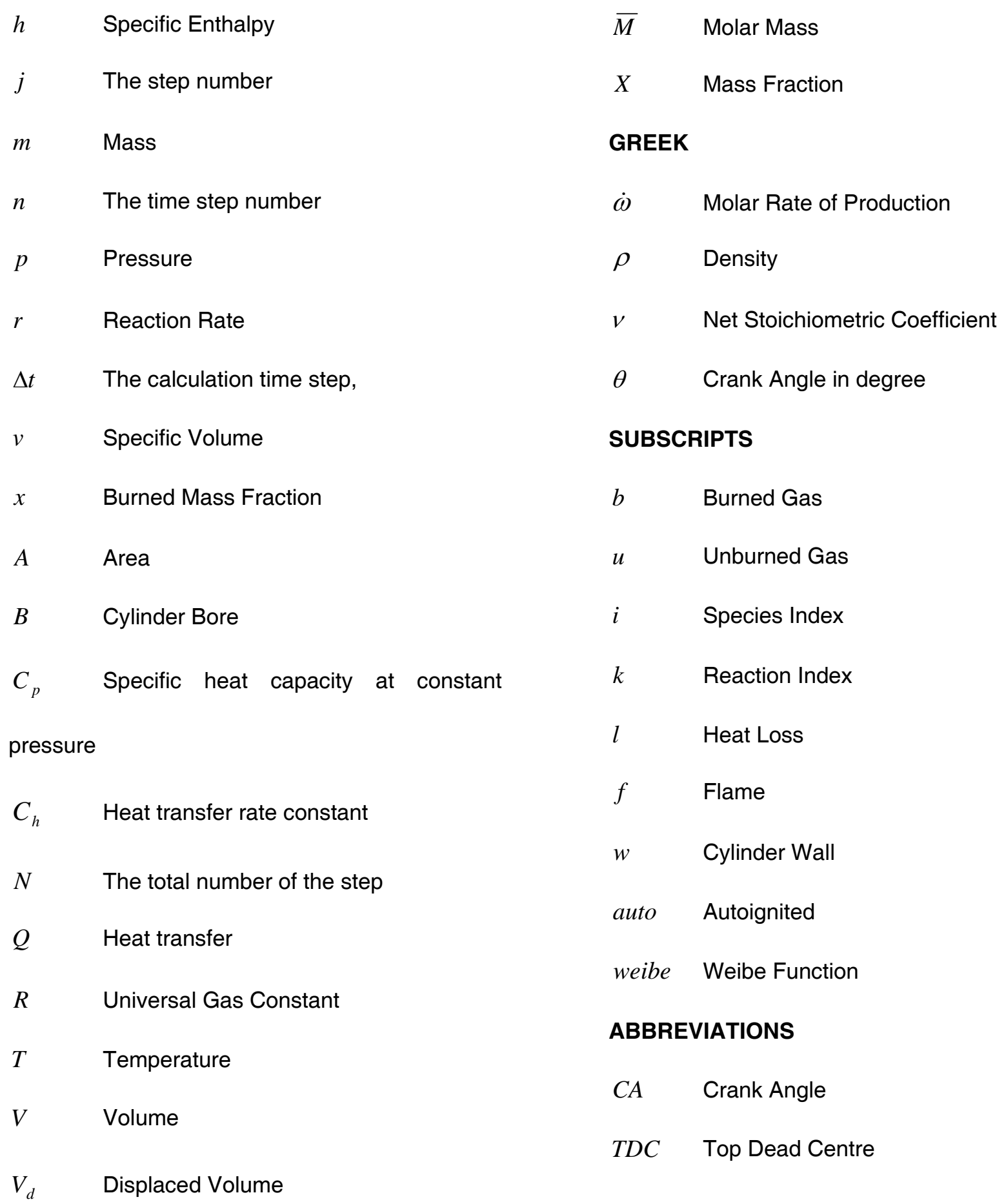




\section{INTRODUCTION}

Modern spark ignition (SI) engines are being designed to operate close to its limits caused by knock to achieve high brake mean effective pressure (BMEP), optimum brake specific fuel consumption (BSFC) and low emissions. It is generally acknowledged that knock in SI engines is caused mainly by the auto ignition of the unburned air and fuel mixture ahead of the flame front. It results in steep pressure gradients that spread in the form of pressure waves in the combustion chamber. These pressure waves then lead to undesirable knocking and ringing noise to the vehicle driver and can cause damages to engine components at sufficiently high intensities.

Chemical kinetic mechanisms play an important role in modelling spontaneous auto ignition. These are generally categorized into detailed [1,2], lumped [3], reduced $[4,5,6]$, and global models $[7,8]$ according to the numbers of the reactions and the species [9]. The detailed chemical kinetic mechanisms were developed mostly by adjusting reaction rate parameters and thermal chemical data to fit experimental data. The other types of mechanisms were either extracted from the detailed mechanisms by taking computerized reaction sensitivity analysis like the lumped models, or derived by simplifying the chemical reaction processes into a few generalized chain branching reactions and fitting the reaction parameters for the experimental results like the reduced and global models. The experimental facilities in the study of chemical kinetic mechanisms are mainly engine-like devices such as closed vessels, flow reactors, shock tubes or rapid compression machines that are operated under homogeneous charge compression ignition $(\mathrm{HCCl})$ conditions. Auto ignition behaviour of the unburned mixture under $\mathrm{SI}$ engine combustion is different from that under $\mathrm{HCCl}$ condition, but mechanisms directly derived from $\mathrm{SI}$ engines were scarce due to the complex combustion process. If these $\mathrm{HCCl}$ mechanisms are applied to model the auto ignition of the unburned mixture under SI engine combustion, certain reaction rate parameters at varying operation conditions will have to be tuned to agree with the experimental data.

There are various levels of engine models having the potential to be coupled with combustion kinetics to simulate SI engine combustion and autoignition, but each comes with inherited advantages and disadvantages. Computational fluid dynamics (CFD) modelling coupled with detailed combustion chemical kinetic mechanisms showed a potential to mimic the engine knock by considering temporal and spatial variance of the properties of the unburned gas mixtures, but requires massive computation resources [10]. Single-step $[11,12]$ and highly simplified multi-step kinetic mechanisms $[13,14,15]$ have 
been linked into the CFD simulations to simplify the calculations, but still computationally expensive. Zero-dimensional modelling technique provides much higher computational efficiency and has been extensively developed as engine design tools. However, most conventional zone models incorporate thermodynamic models and chemical equilibrium combustion models $[16,17]$. They are functionally unable to describe the knock phenomenon. Various combustion chemical kinetic mechanisms, such as Shell auto ignition model [18], reduced chemical kinetic mechanism [19], and semi-detailed chemical kinetics [20], have been introduced into zero-dimensional thermodynamic engine models to simulate the knock phenomenon. These zero-dimensional knock models have shown the potential to model and analyze the engine knock behaviour. However, the chemical kinetic mechanism employed was generally based on iso-octane, which is different from the fuel in the real world.

Tanaka mechanism $[5,6]$ uses identical hydrocarbon oxidation schemes for both iso-octane and $\mathrm{n}$-heptane with 12 reactions in each scheme and includes an interaction reaction between $\mathrm{n}$-heptane and iso-octane. By introducing further non-hydrocarbon mechanisms, the Tanaka mechanism consists of 55 reactions with 32 species. It is capable of simulating the combustion and autoignition behaviour of primary reference fuels. The mechanism has been tested in a wide range of $\mathrm{HCCl}$ conditions in a rapid compression machine. It is the interest of this research work to introduce the Tanaka mechanism into an early in-house developed zero-dimensional SI engine model and tune some of its key rate parameters to simulate SI combustion and knock performances.

\section{THE MODEL}

The model developed in the study is a zero-dimension based SI engine combustion model combined with tuned Tanaka kinetic mechanism. In the model, the in-cylinder gas mixtures are divided into three individual zones according to their different thermodynamic states and compositions as shown in Figure 1. The unburned zone is made of unburned mixture of fuel and air in front of the propagating flame. No burned residuals are considered. The burning zone is the reaction zone of the thin flame front, transporting mass and energy from the unburned to burned gas regions. The burned zone indicates the region consisting of burned products. The combustion chemical kinetic mechanism is applied in both the unburned zone to predict the oxidation reactions of the unburned air and fuel mixture, and in the burned zone to calculate the thermal performance of the burned gas. The burning zone at the thin flame front is assumed to have no volume and regarded as a transporting process [21,22]. It is modelled by chemical 
equilibrium calculations [23].

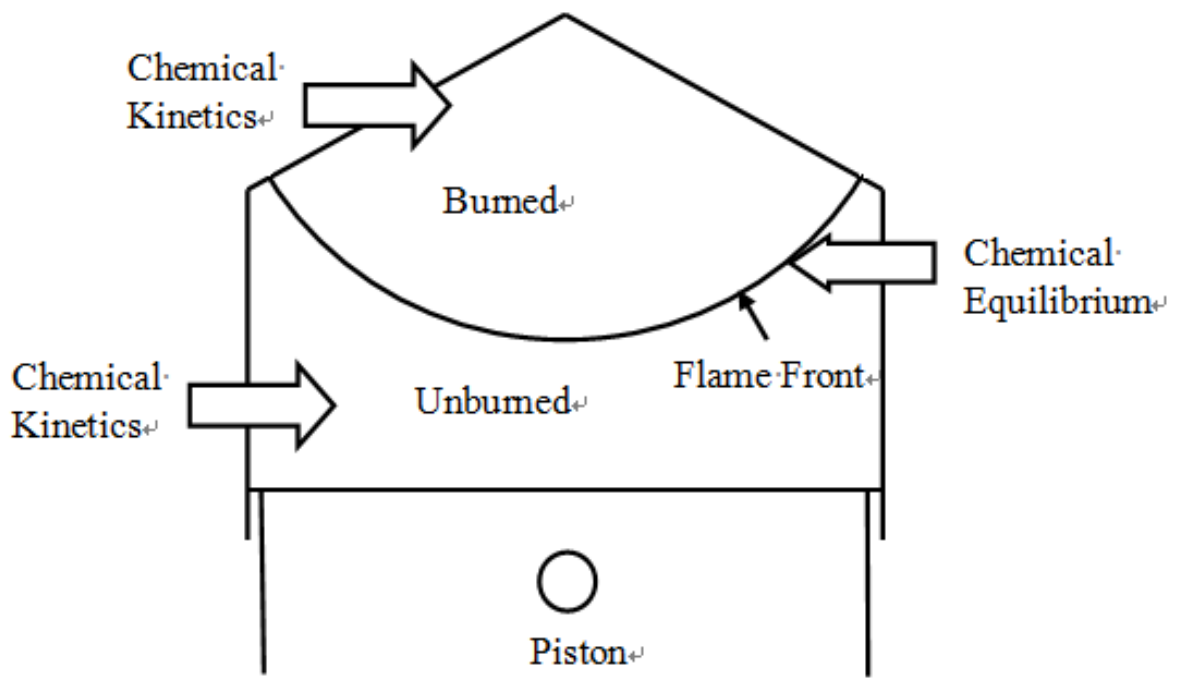

Figure 1: Three-zone combustion chamber

\subsection{Basic Model}

The foundation of the zonal model is based on applying the mass and energy conservation principles on both unburned and burned zones. The major assumptions of the basic model are ideal gas engine charge, perfect homogeneous fuel-air mixture, and uniform in-cylinder pressure.

Mass Conservation - In the unburned zone, when pressure and temperature are sufficiently high, the air and fuel mixture is no longer stable and cool flame reactions starts. The reactions may further lead to auto ignition if the temperature further increases. This is analyzed in the model by introducing chemical kinetics to the unburned zone. Applying the mass conservation principle to the unburned zone, the change rate of the mass fraction of a species $i$ in the unburned zone, $X_{i, u}$, is then expressed as

$$
\frac{d X_{i, u}}{d t}=\frac{\bar{M}_{i} \dot{\omega}_{i}}{\rho_{u}}
$$

where, $\bar{M}_{i}$ is the molecular mass, $\dot{\omega}_{i}$ is the volume specific molar production rate, and $\rho_{u}$ is the density of the unburned zone. The subscript $i$ denotes a species in the mixture.

In the burned zone, the mass fraction change of each species is affected by two factors, the formation by the flame reactions, and the formation and consumption by the post flame kinetic reactions. The total mass in the burned zone, $m_{b}^{\prime}$, after taking the transferred mass from the burning zone $\Delta m$ is 


$$
m_{b}^{\prime}=m_{b}+\Delta m
$$

where $m_{b}$ is the burned zone mass before taking the transferred mass.

The mass fraction of a species $i$ after mixing with the mass transferred from the burning zone is therefore expressed as

$$
X_{i, b}^{\prime}=\frac{\Delta m \cdot X_{i, f}+m_{b} \cdot X_{i, b}}{m_{b}^{\prime}}
$$

where the $X_{i, f}$ is mass fraction of a species $i$ in the transferred mass from the burning zone which is equal to that in the flame front, and $X_{i, b}$ is the existing fraction before the transfer, the subscript $b$ indicates unburned and burned zone.

Substituting Eq.(2) into Eq.(3) yields the mass fraction change of a species $i$ due to formation by the flame reactions. Adding the formation and consumption by the post flame reactions, the mass fraction change of a species $i$ in the burned zone is then obtained

$$
\frac{d X_{i, b}}{d t}=\frac{1}{m_{b}^{\prime}} \frac{d m_{\mathbf{b}}}{d t} \cdot\left(X_{i, f}-X_{i, b}\right)+\frac{\bar{M}_{i} \dot{\omega}_{i}}{\rho_{b}}
$$

Energy Conservation - The energy conservation equation is applied to represent the energy change in the unburned and burned zone. For the unburned zone, it relates the temperature change to the heat transfer $\dot{Q}_{l, u}$, the work due to the volume change, and the energy change due to the chemical kinetic reactions

$$
m_{u} c_{p, u} \frac{d T_{u}}{d t}=\dot{Q}_{l, u}+V_{u} \cdot \frac{d p}{d t}-V_{u} \cdot \sum_{i=1}^{n} \omega_{i, u} \cdot \bar{M}_{i} \cdot h_{i, u}
$$

where $h$ is the specific enthalpy, $c_{p}$ is the specific heat capacity at constant pressure, $V$ is the zone volume, $p$ is the cylinder pressure, and $T$ is the zone temperature.

For the burned zone, the effect of the energy transferred from the burning zone, $\dot{m}_{b} \cdot\left(h_{f}-h_{b}\right)$, on the temperature change needs to be taken into account which gives 


$$
m_{b} c_{p, b} \frac{d T_{b}}{d t}=\dot{Q}_{l, b}+V_{b} \cdot \frac{d p}{d t}+\dot{m}_{b} \cdot\left(h_{f}-h_{b}\right)-V_{b} \cdot \sum_{i=1}^{N_{s}} \omega_{i, b} \cdot \bar{M}_{i, b} \cdot h_{i, b}
$$

Heat Transfer - The heat transfer of the unburned zone in the model consists of two parts, the heat convection between the unburned gas and the cylinder wall and the heat convection between the unburned gas and the flame front,

$$
Q_{l, u}=h_{\text {conv_w }_{-}} \cdot A_{u} \cdot\left(T_{u}-T_{w}\right)+h_{\text {conv }_{-} f} \cdot A_{f} \cdot\left(T_{u}-T_{f}\right)
$$

where $A_{u}$ is the contact area between the unburned gas and the cylinder wall. $A_{f}$ is the contact area between the unburned gas and the flame front which is estimated as $A_{f}=C_{A} \cdot A_{b}$, where $C_{A}$ is an adjustable constant, and $\boldsymbol{A}_{\boldsymbol{b}}$ is the area of burned gases in contact with the cylinder wall and is calculated by an empirical function [16]

$$
A_{b}=\left(\frac{\pi \cdot B^{2}}{2}+\frac{4 \cdot V}{B}\right) \cdot x_{\text {flame }} \frac{1}{2}
$$

where $X_{\text {flame }}$ is the mass fraction burned by flame propagation and $B$ is the cylinder bore.

The heat transfer coefficients $h_{\text {conv }}$ and $h_{c o n v_{-} f}$ have been simulated using the Woschni correlation $h=C_{h} B^{-0.2} p^{0.8} w^{0.8} T^{0.53}$, where $C_{h}$ is the heat transfer rate constants and $w$ is a characteristic speed [24]. The thermal radiation from the burned zone to the cylinder wall is modelled by the Stefan-Boltzmann law $Q_{\text {rad }}=A_{w} \sigma T^{4}$, where $\sigma$ is the Stefan-Boltzmann constant $5.67 \times 10^{-8}\left[\mathrm{~W} / \mathrm{m}^{2} \mathrm{~K}^{4}\right][25]$.

Mass Fraction Burned - The burned mass in the cylinder consists of two parts, the mass transported from the burning zone due to the flame propagation, and the mass burned in the unburned zone due to the chemical kinetic reactions of the unburned gas auto ignition. Thus, the Mass Fraction Burned (MFB), $x_{b}$, is expressed as:

$$
x_{b}=x_{\text {flame }}+x_{\text {auto-ignition }}
$$

The mass burned by flame propagation in the model is calculated by the Weibe function [25]. The 
burned mass in the unburned zone is due to auto ignition only, and is therefore equal to the mass that have been consumed by the chemical kinetic reactions. Note that the mass burned due to chemical kinetic reactions will only play a significant part when auto ignition starts. This is expressed as

$$
x_{\text {auto-ignition }}=\sum_{i=1}^{3} \sum_{j=1}^{n} m_{u} \Delta X_{i, u, j} \Delta t
$$

where $\Delta t$ is the calculation time step, subscript $j$ is the step number, $i$ is species number where 1 denotes fuel, 2 denotes $\mathrm{O}_{2}$ and 3 denotes $\mathrm{N}_{2}$.

\subsection{Kinetic Mechanism}

Tanaka combustion chemical kinetic mechanism, as listed in Appendix 1, has been employed in this study to model the oxidation of primary reference fuels. It needs to note that the autoignition of the unburned mixture in the $\mathrm{SI}$ combustion is different from that of the $\mathrm{HCCl}$ combustion. In the $\mathrm{HCCl}$ case, the compression, the main driving force of the autoignition, is from the piston only. However, in the SI combustion, the unburned mixture is compressed by both the piston motion and the flame propagation. The later contributes to faster and stronger compression and is heat transfer intensified. Therefore, it is reasonable to conclude that the autoignition in the $\mathrm{SI}$ combustion is stronger than that in the $\mathrm{HCCl}$ combustion, and can be characterized by shorter ignition delay and greater burned rate. The original Tanaka mechanism was developed for the $\mathrm{HCCl}$ combustion, so it needs to be tuned for the $\mathrm{SI}$ engine conditions.

A sensitivity analysis investigating the effect of the reaction rates on the ignition delay and burn-rate [5] indicated that the alkyl radical formation reactions in the Tanaka mechanism (R6 and R18 generally expressed as $\mathrm{RH}+\mathrm{OH}=>\mathrm{R}+\mathrm{H} 2 \mathrm{O}$ ) have the greatest influence on both the ignition delay time and the burn rate. The enhancement of their pre-exponential factors of the rate-constants leads to a shorter ignition delay and a higher burn-rate. This phenomenon is attributed to the role of alkyl radical formation reactions in the oxidation chemistry, where both reactions represent the attack of the active radical $\mathrm{OH}$ to abstract the atom $\mathrm{H}$ from fuel molecules. This is believed to be the primary chemical path that is responsible for fuel consumption [26]. The kinetic parameters in R6 and R18 therefore need to be enhanced in order to tune the mechanism to the level of autoignition under SI conditions.

The enhancement of the kinetic parameters in reactions R6 and R18 have no effects on the low $-6-$ 
temperature oxidation reactions of the unburned gas mixture before knock occurring or under the conditions that lead to no autoignition. This is because that these two reactions are only actively responsible for the parent fuel decomposition when the temperature rises to the intermediate and high regimes, where $\mathrm{OH}$ radicals can be built up and become the critical chain-carrying radicals $[27,28]$. The modified mechanism is therefore capable to simulate the low temperature reactions of the unburned gas mixture that may or may not lead to knock.

After applying the Tanaka chemical kinetic model into the three-zone engine model, a sensitivity analysis was conducted to study the influence of the pre-exponential factors of reactions R6 and R18 on knock position, peak cylinder pressure, knock intensity and combustion duration. Figure 2 shows the calculated knock position and peak cylinder pressure at varying enhance factors applied to the pre-exponential factors of R6 or R18. Both reaction rate parameters need to be tuned simultaneously since the two reactions play the same roles in the chain branching mechanisms for $n$-heptane and iso-octane, respectively. The modelled engine condition is $900 \mathrm{RPM}$, spark ignition timing of $6^{\circ}$ before top dead centre (BTDC), intake pressure of $1.0 \mathrm{bar}$, and air to fuel ratio (AFR) of 13:1. The fuel input into the calculation is a primary reference fuel with $95 \mathrm{RON}$. In the baseline case, the pre-exponential factors are set the same as the ones in the Tanaka mechanism. It can be seen that as the pre-exponential factors increase, the knock occurring position advances towards TDC and the peak in-cylinder pressure increases. This justifies the effect of enhanced factors on the ignition delay. As the ignition delay time is shortened, autoignition occurs early towards the TDC, which leads to higher peak pressure.

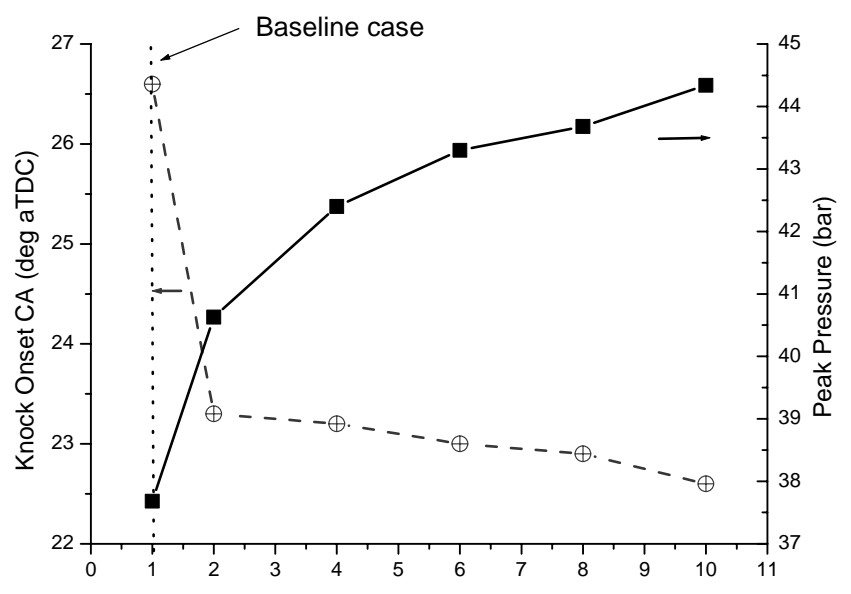

Factors applied to the pre-exponential factors of R6 and R18

Figure 2: Calculated knock position and peak pressure vs. Enhancing Factors in R6 and R18 
Figure 3 shows the calculated knock intensity and combustion duration at varying pre-exponential factors of reaction R6 and R18. It can be seen that as the factors increases, the knock intensity increases and the combustion duration decreases attributing to the effects of the factors on accelerating the entire reaction processes.

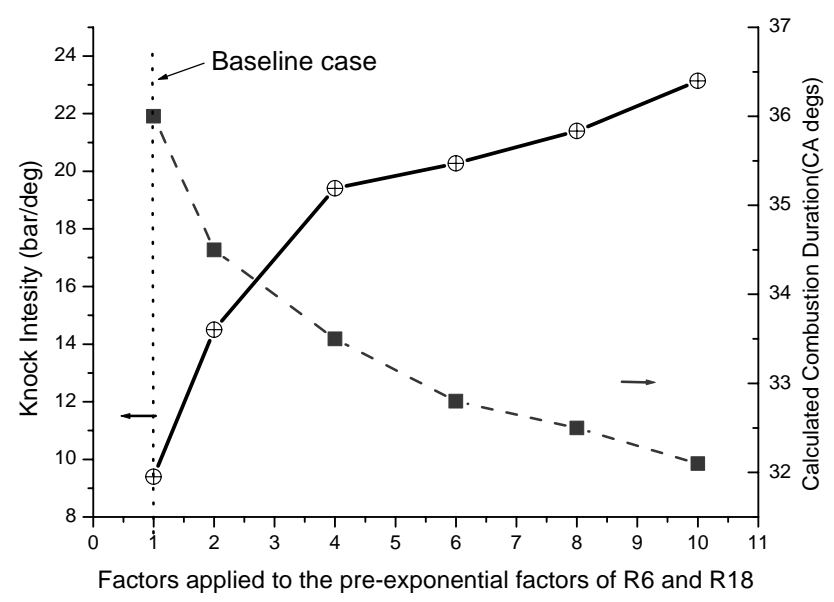

Figure 3: Calculated knock intensity and combustion duration vs. Enhancing Factors in R6 and R18

The results show that the increase of the enhance factors from 1.0 to 6.0 leads to knock position being advanced by about $23 \%$, the peak pressure being increased by around $16 \%$ and knock intensity being raised by about $100 \%$. Further increasing the enhance factors from 6.0 to 10.0 can only affect these three parameters by about $3 \%, 2 \%$ and $15 \%$, respectively. Thus, it can be concluded the enhance factor of the value of 6.0 is the turning point and has been employed in this work.

\subsection{Equilibrium Burning Zone}

The burning zone is the flamelet reaction zone transporting mass and energy from unburned to burned gas regions. In this study, the burning zone is assumed as an adiabatic region at chemical equilibrium. During each calculation step, the mass entrained into the flame front is assumed to be burned and transferred into the burned gases instantaneously.

The same thermodynamic data and chemical species in Tanaka mechanism are selected to be included in the equilibrium chemistry. The equilibrium state of the gas mixture in the burning zone is determined by minimizing the Gibbs free energy $\Delta G \approx 0$, which serves as a criterion of chemical equilibrium. The thermal properties and the equilibrium chemical composition of the burning zone are calculated using the STANJAN equilibrium program [29]. 


\subsection{Numerical Solver}

The combination of the basic engine model, the mass fraction burned model and the kinetic combustion model forms a set of coupled Ordinary Differential Equations (ODEs). This includes 66 simultaneous variables for temperatures and species mass fractions as a function of crank angle. Due to the incorporation of chemical kinetics into the combustion system, the set of equations involves enormous disparities in the characteristic time scales for the response of different species during the occurrence of auto ignition. These kinetics equations were solved in the model using a Double-precision Variable-coefficient Ordinary Differential Equation (DVODE) solver developed for the solution of both stiff and non-stiff systems.

An in-house FORTRAN code, LUCKS (Loughborough University Chemical Kinetics Simulation), integrating the DVODE solver for the ODEs, has been developed to simulate combustion systems with chemical kinetics. Figure 4 shows the model flowchart. The simulation is executed from Intake Valve Closing (IVC). A link file with the information of the kinetic mechanism, the thermal data, and an input data file consisting of the initial operating conditions and the engine specifications are input to the function block to calculated the parameters used in the governing equations. The function block includes the subroutines for the calculation of cylinder volume, mass fraction burned, and the zone mixture properties. The governing equations are solved by the DVODE solver and the outputs (zone temperatures and zone species mass fractions) are used to update the in-cylinder pressure and routed back to the function block for the next calculation step. Next, the calculated pressure is also routed back to the function block for the next calculation step. The calculation stops at the timing of Exhaust Valve Opening (EVO). The governing equations are integrated simultaneously at a calculation time step of 0.1 crank angle degrees in the model. 


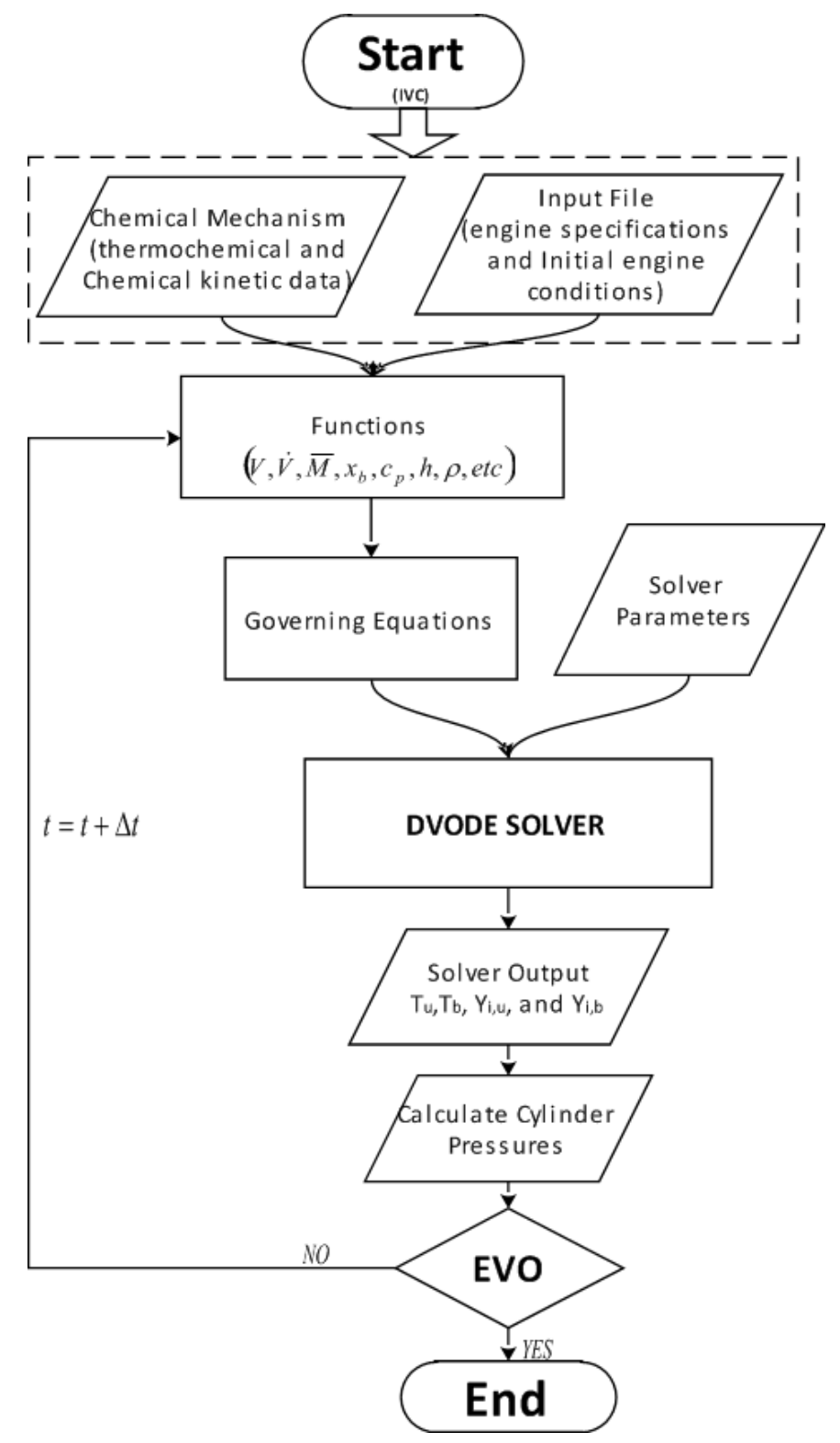

Figure 4: The structure of the LUCKS program

\section{MODEL VALIDATION}

\subsection{Tests and Knock Identification}

The engine used for the model validation in this work is a single cylinder, 4-stroke Ricardo E6 research SI engine. The engine specifications are detailed in Table 1.

Table 1 Engine parameters

\begin{tabular}{ll}
\hline Stoke & $111.2 \mathrm{~mm}$ \\
Bore & $76.2 \mathrm{~mm}$ \\
\hline
\end{tabular}




\begin{tabular}{ll}
\hline Con rod length & $240.5 \mathrm{~mm}$ \\
Compression ratio & $10: 1$ \\
IVO & $9 \mathrm{deg}$ BTDC \\
IVC & $37 \mathrm{deg}$ ABDC \\
EVO & $41 \mathrm{deg}$ BBDC \\
EVC & $10 \mathrm{deg}$ ATDC \\
\hline
\end{tabular}

The engine was equipped with a pressure transducer and the data was recoded at an interval of one-tenth crank angle degree. A LabVIEW based engine data acquisition system was used to record 50 consecutive engine cycles data at each test condition.

Knock detection has been a widely researched subject. It was found that the pressure traces under knocking conditions have two distinct features: the pressure fluctuation and the sharp pressure rise $[30,31,32]$. In this work, the start of the first distinct transition in the slope of the cylinder pressure trace, which is followed by consecutive pressure fluctuation, is taken as the knock onset position as shown in Figure 5.

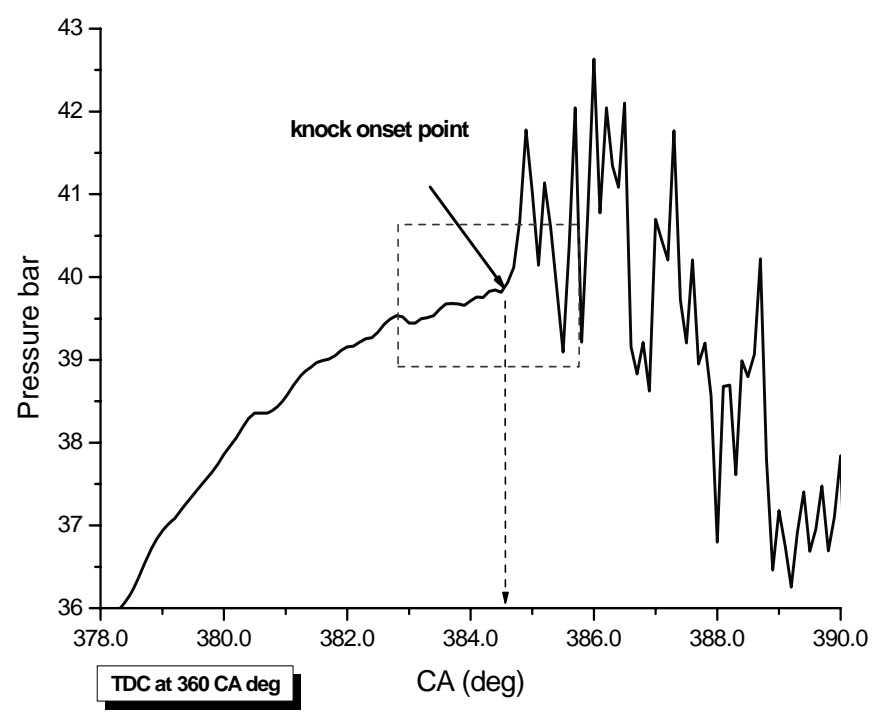

Figure 5: Knock position on a typical measured pressure trace

This transition point is identified by calculating the pressure slope change rate $(\mathrm{K})$ across every three adjacent values on the pressure curve:

$$
K=\frac{\left(p_{n}-p_{n-1}\right) / \Delta \theta-\left(p_{n+1}-p_{n}\right) / \Delta \theta}{\Delta \theta}
$$


It was found that a threshold value of $30 \mathrm{bar} / \mathrm{CA}^{2}$ corresponds well with the knock occurrence in the tests and has been used to identify the knock in this study.

The knocking level is evaluated by knock intensity, which is defined as the maximum amplitude of pressure increase rate. Figure 6 shows the knock intensity against knock positions of 43 knocking cycles identified from 50 consecutive measured cycles at 900 RPM, $4^{\circ}$ BTDC spark timing, AFR of 13 and at wide-open throttle (WOT). It shows that the earlier the knock occurs, the stronger the knock intensity is. This trend agrees with the results reported elsewhere [33,34].

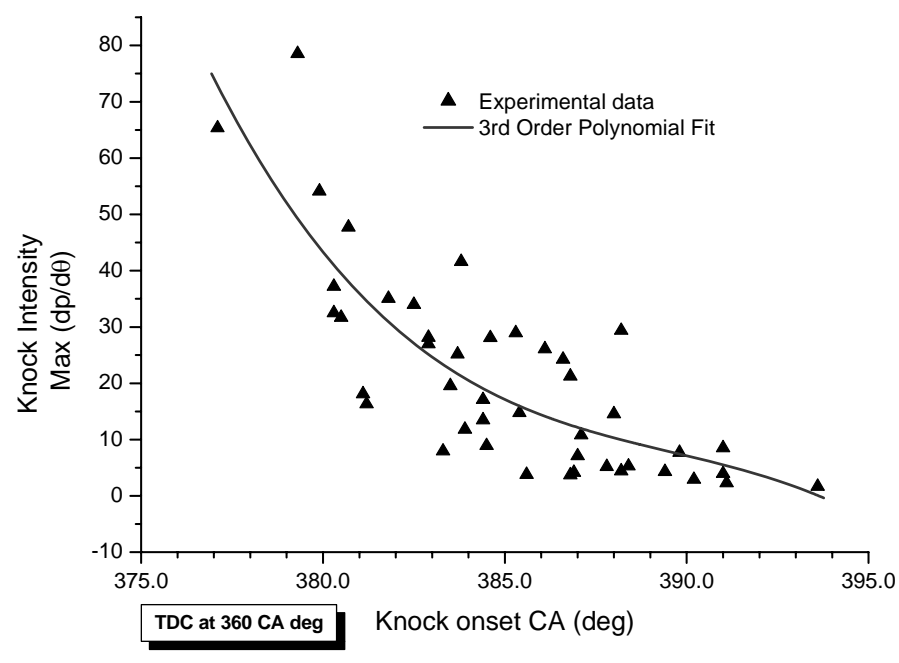

Figure 6: Knock intensity .vs. knock positions of the identified knocking cycles

\subsection{Validation}

The model developed in this work was to simulate engine combustion performances under both knock and non-knock conditions. If the engine operates without knocking, the combustion kinetics employed in the model will be low temperature reactions dominated, and thus no auto ignition occurs. Figure 7 shows the comparison between calculated and measured in-cylinder pressure at a no knock condition. The measured in-cylinder pressure was averaged over 50 consecutive cycles at WOT condition with a speed of 1500 rpm, a spark ignition timing of $9^{\circ}$ BTDC, and an AFR of 10 . The same engine conditions were used in the model. The fuel rich mixture decreases the fuel conversion efficiency that leads to a poor combustion without any knock. It can be seen that the calculated in-cylinder pressure agrees well with the measured results. It shows that the model with the modified combustion kinetics does not affect its low temperature reaction mechanism and has the capability to reflect the non-knocking operation conditions.

$-12-$ 


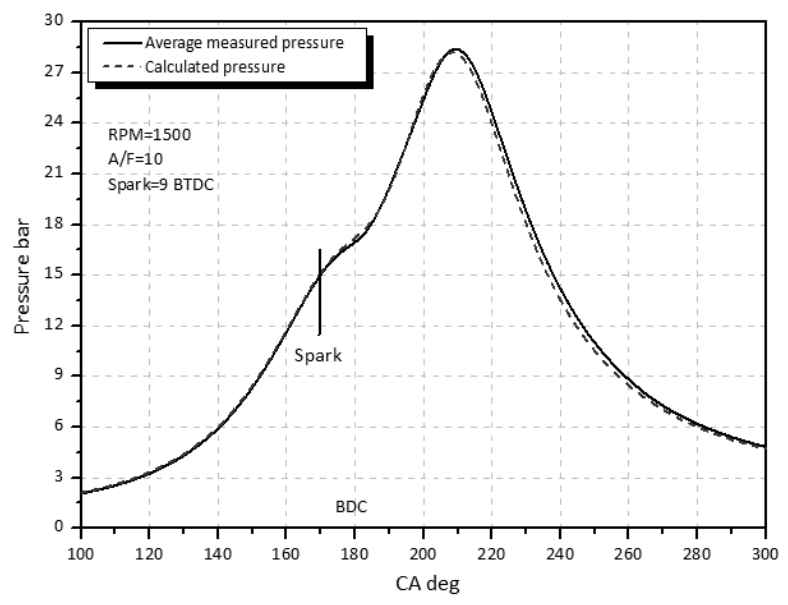

Figure 7: Calculated and measured in-cylinder pressure under non-knocking condition

As the mixture strength reduces, the oxygen availability improves and the combustion temperature increases. With the same engine operation conditions, as the $A / F$ ratio increases, the combustion improves until a level that auto ignition of unburned mixture before the flame front starts, which leads to engine knock. To validate the model prediction of knock characteristics (Knock Intensity, Knock Onset and Peak Pressure), the simulation results of these characteristics are compared with the average value of the experimental data of the knocking cycles. Figure $8 a-8 c$ show the peak pressure, knock intensity and knock onset position of measured values from 50 consecutive measured cycles, the average experimental data and the calculated data from the model. The engine test conditions are $1500 \mathrm{RPM}, 9^{\circ}$ BTDC spark timing, AFR of 13 and WOT. The disparity of the measured cycle data is attributed to the significant cycle-to-cycle variation under knocking conditions. The calculated data agrees well with the average experimental data, which shows the capability of the developed model in predicting knock characteristics.

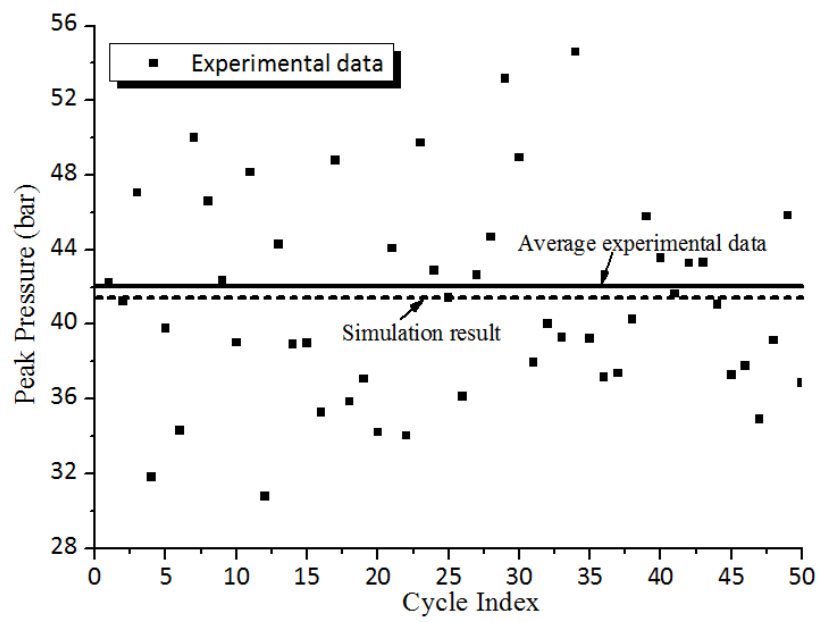


Figure 8a

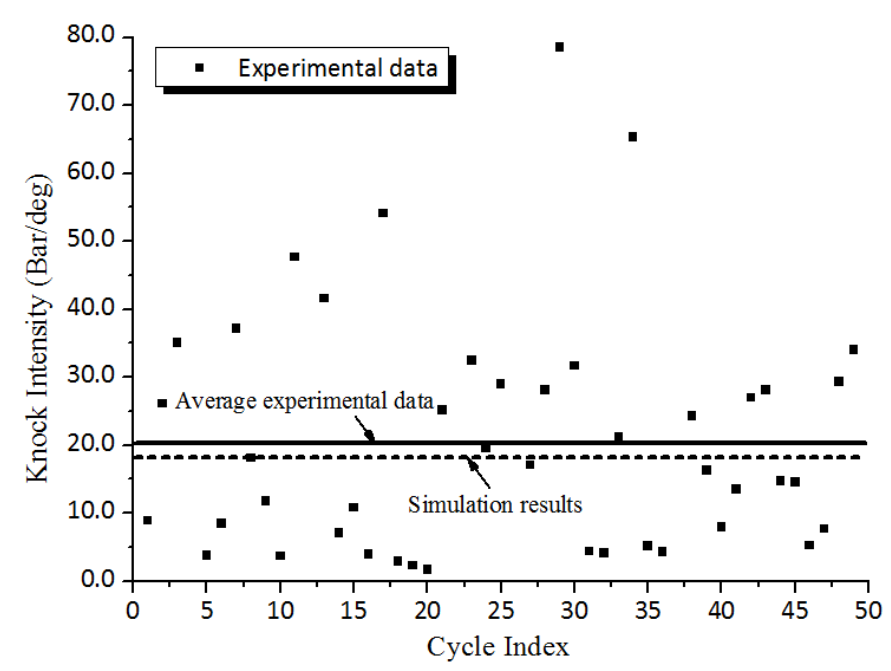

Figure $8 b$

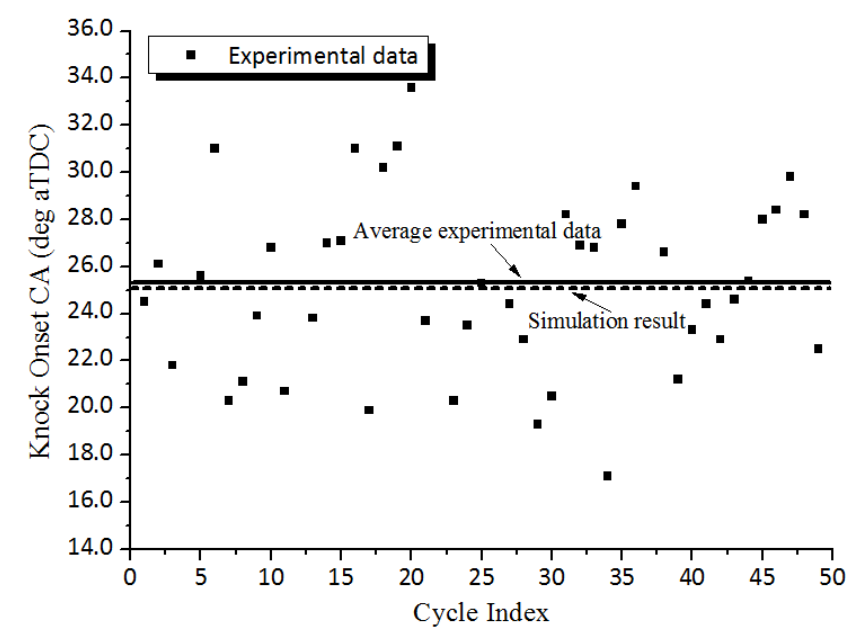

Figure 8c:

Figure 8: Comparison of knock characteristics between calculated and measured data

Figure 9 shows the calculated in-cylinder pressure with varying AFR at a fix speed of $1500 \mathrm{rpm}$ and a park ignition timing of $9^{\circ} \mathrm{BTDC}$. It shows that knock is not detected until the $\mathrm{A} / \mathrm{F}$ ratio is increased to 11 , which is indicated by a smooth pressure curve at $A F R=10$ and sharp pressure increase at $A / F$ ratio of 11 , 12 and 13. 


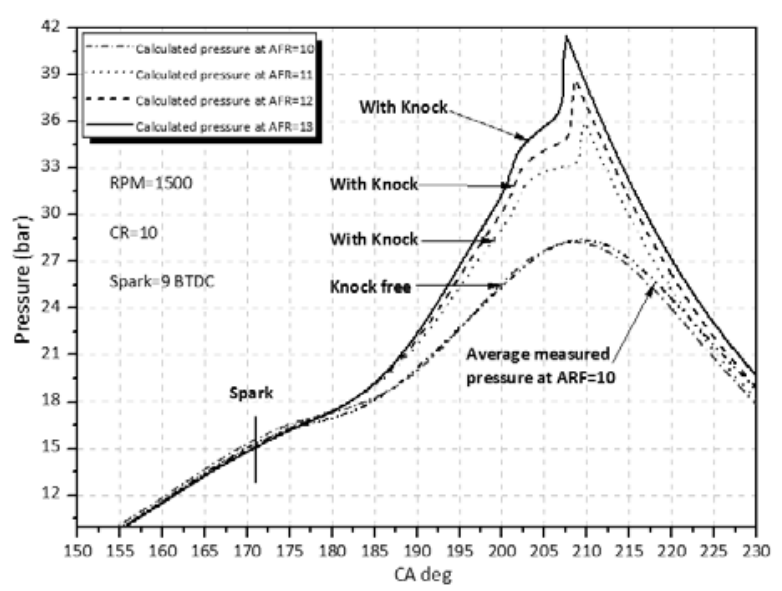

Figure 9: Calculated in-cylinder pressure at varying AFR

Figure 10 summarises the calculated and measured peak cylinder pressure with varying AFR. It shows that peak cylinder pressure increases as the A/F ratios increases. The model overall slightly under predicted the cylinder peak pressure, by about $5 \%$ at the maximum. The difference may due to the heat transfer rate coefficient correlation employed in the model, which may not be sensitive enough to the variation of $A / F$ ratios especially under knock conditions. Furthermore, the heat transfer across the flame front has been calculated with assumption that the flame front area is twice the surface area of the burned zone in the model; this causes further errors in predicting the heat transfer.

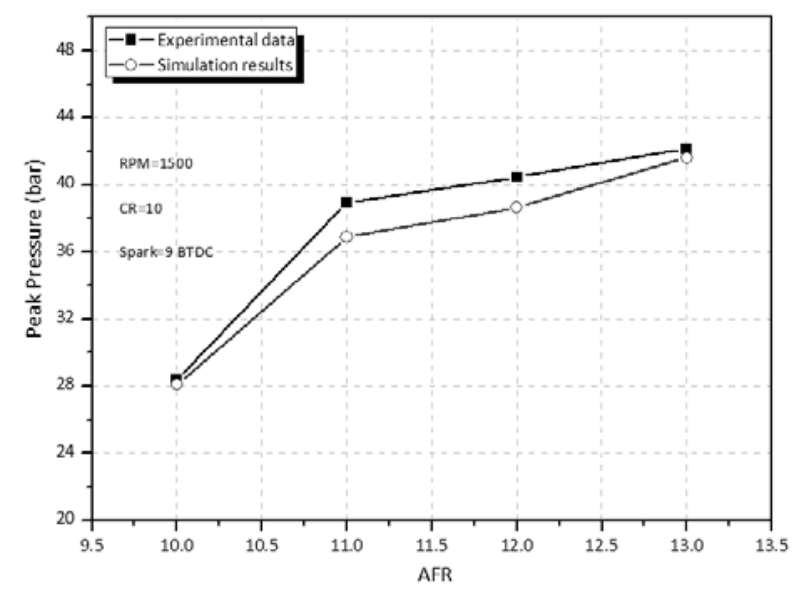

Figure 10: Calculated and measured peak pressure at varying AFR

Figure 11 summarises the calculated and measured knock onset position and knocks intensity at varying AFR. Three regions can be identified, the knock region, the non-knock region, and the transition between the two. At the tested engine conditions, the knock region is between the A/F ratios of 11 to 13 . When the $A / F$ ratio is lower than 10 , there is no knock being detected. In the region of 10 to 11 , the engine is under and through the transition. It can be seen that both calculated and measured knock 
position advances and knock intensity increases as the $A / F$ ratio increases. The simulated knock onset position is slightly less predicted at rich conditions, about $0.6^{\circ}$ later than the measured position at AFR of 11. The difference reduces as the mixture getting leaner. As the results, the predicted knock intensity is about $10 \%$ lower than the measured one at lean conditions. Again, the difference may due to over calculating of heat loss at lean conditions since the heat transfer rate correlation employed in the model is not sensitive enough to variation of $A / F$ ratios.

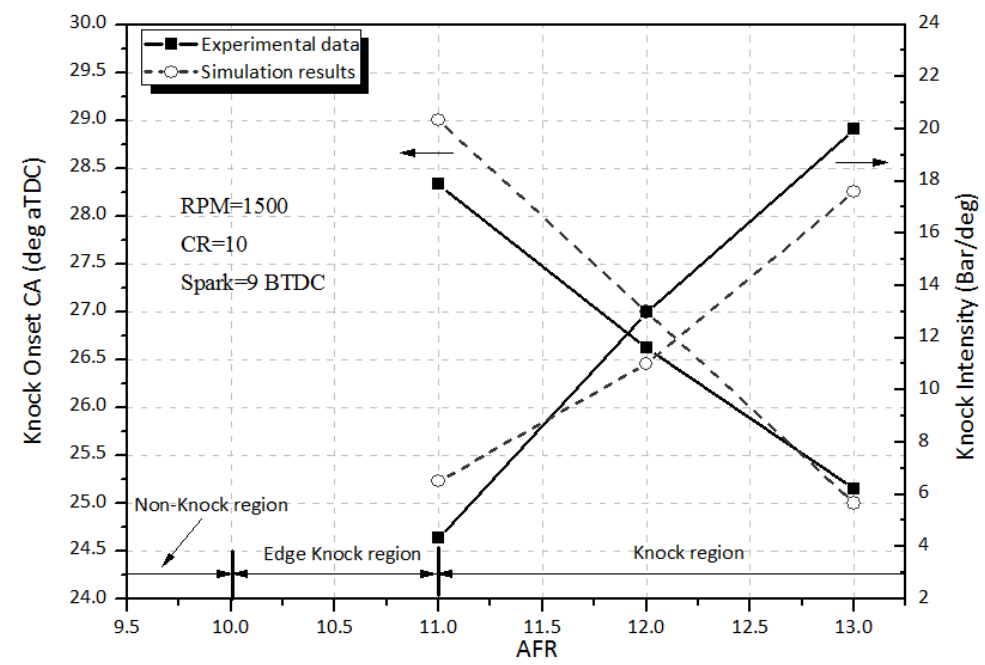

Figure 11: Calculated and measured knock onset position and knock intensity at varying AFR

Engine speed determines the time availability of the combustion cycle. Knock is an auto ignition related phenomenon that is dominated by the time dependent chemical kinetics. It is therefore a logical conclusion that as the engine speed increases, the time availability of the combustion cycle decreases, which leads a delayed knock in terms of engine crank angle. This phenomenon has been tested and simulated in the study and Figure 12 shows the calculated and measured results. The engine operating conditions during the test and as the inputs to the model are $4^{\circ}$ BTDC fixed spark timing, AFR of $14: 1$ and WOT. Both the measured and calculated results confirm that the knocking position in terms of engine crank angle is delayed as engine speed increases. The simulated knock position at low engine speed is slightly later than the measured position while at high speed it becomes a bit earlier. 


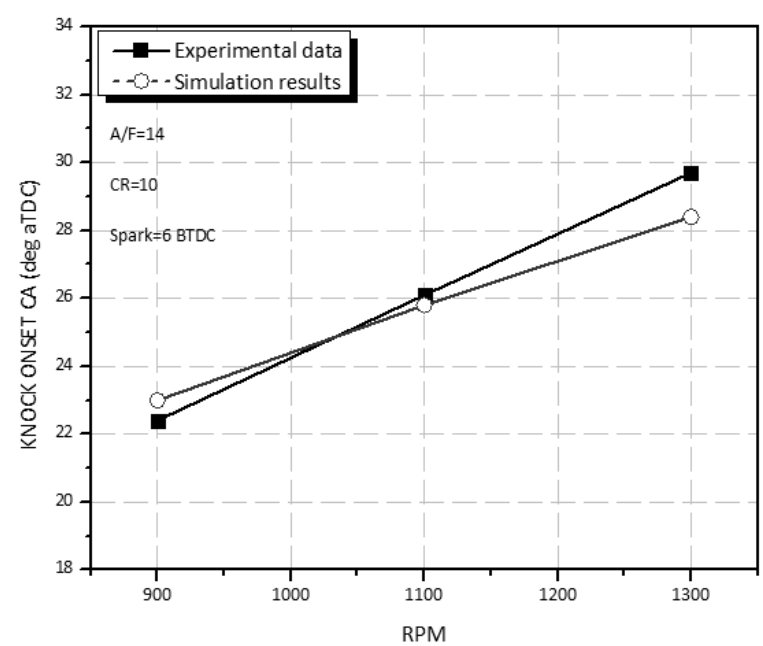

Figure 12: Comparison of calculated and measured knock onset positions in respect of RPM

Figure 13 shows the calculated and measured peak cylinder pressure at knocking conditions at varying engine speeds. It shows that peak cylinder pressure decreases as the engine speed increases. The model overall over predicted the cylinder peak pressure.

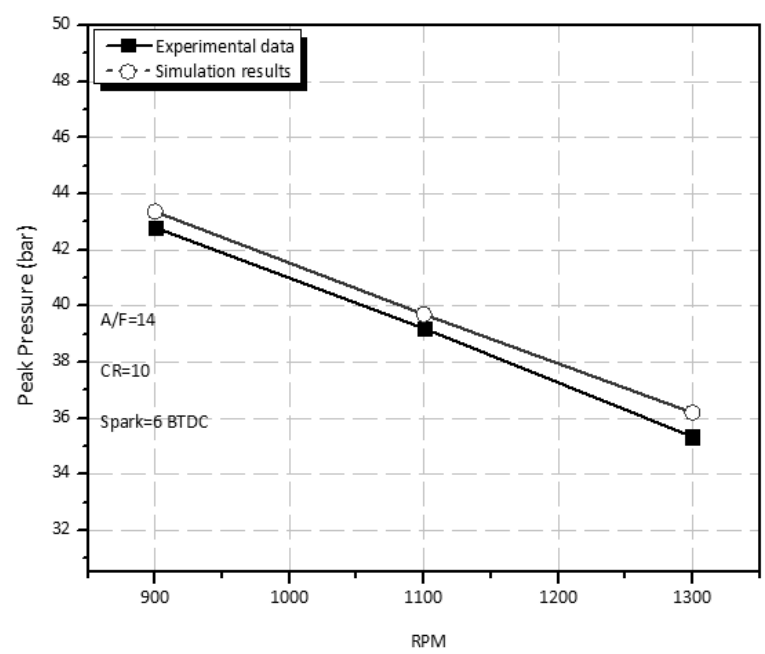

Figure 13: Comparison of calculated and measured peak pressures in respect of RPM

Figure 14 shows the calculated and measured knock intensity at varying engine speeds. Reducing the engine speeds results in an increase of the duration of time for which the end-gas is subjected to high pressure and temperature environment. This leads to the build-up of the radical pool to consume major fraction of the fuel in the gas and causes auto ignition. The longer the end gas resides in high temperature and pressure environment, the earlier and harder it is for the end gas to auto ignite. 


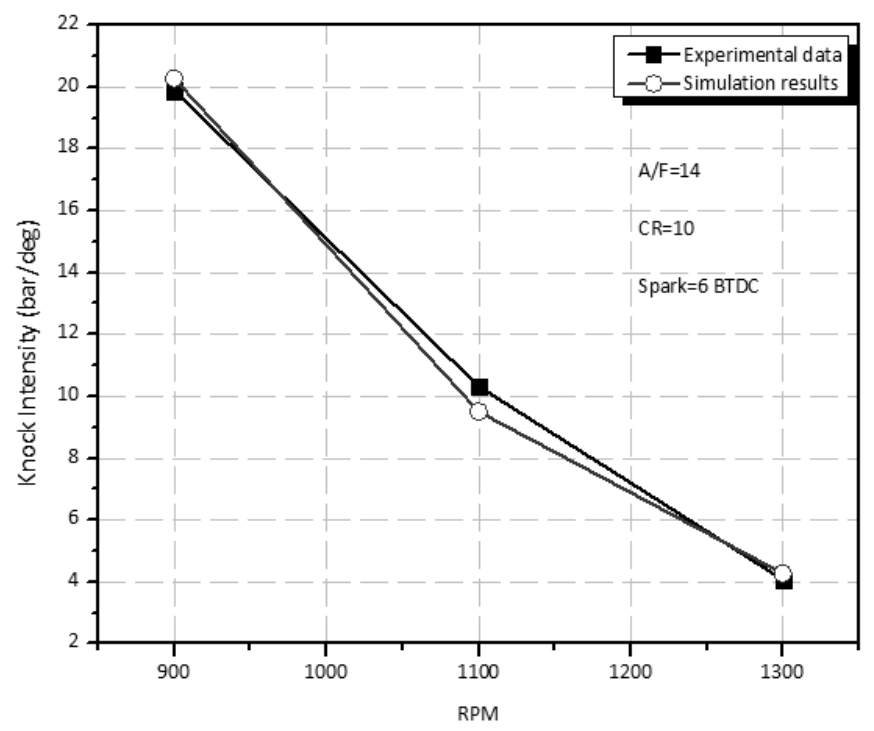

Figure 14: Comparison of calculated and measured knock intensity in respect of RPM

\section{APPLICATIONS}

Figure 15 shows the calculated burned mass fraction with and without auto ignition under an engine condition of 1500 RPM, spark timing of $9^{\circ}$ BTDC, air to fuel (A/F) ratio of 13 , and Wide Open Throttle (WOT) full load condition. The one without auto ignition is calculated directly using the Weibe function, and the one with auto ignition is calculated by the model with the same Weibe function parameters. It can be seen that the two curves overlap until the level of about $45 \%$. When auto ignition, the knock, occurs in the unburned zone, the burned mass fraction suddenly accelerates due to the auto ignition of the mixture in the unburned zone. Clearly, to merge the auto ignited mass into the burned mass shortens the overall combustion duration than that defined by the Weibe function.

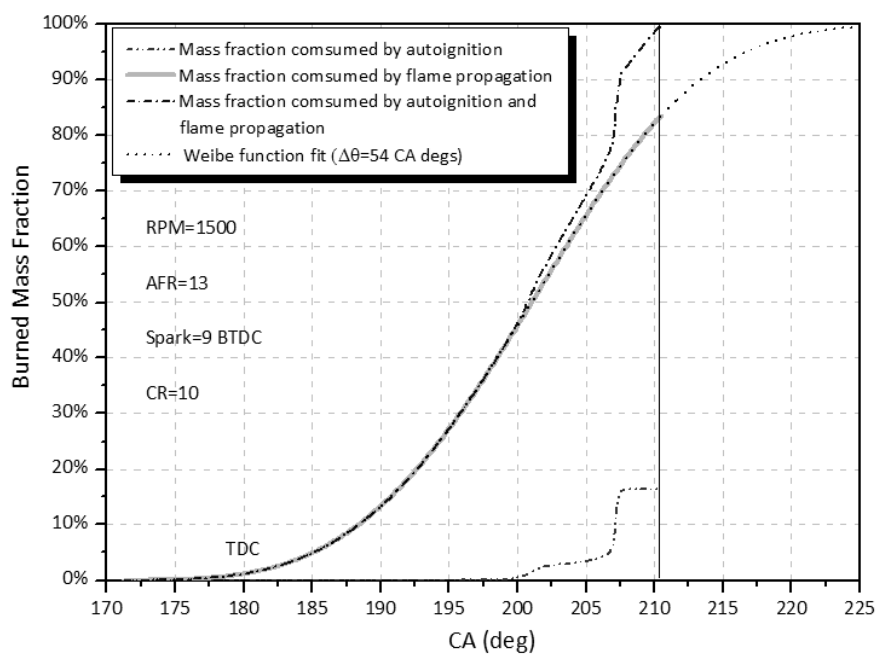

Figure 15: MFB with and without unburned mixture auto ignition 
Intake air pressure boosting has been widely used in achieving high BMEP outputs fuel efficiency. The strategy is seriously limited by the knock problem. Spark timing retardation is an efficient method to avoid the knock, but can significantly reduce the engine combustion efficiency. A good understanding in to the relationship among the boost pressure, combustion quality and spark timing retardation is necessary. The zero-dimensional 3-zone model developed in this work offers such a potential. Figure 16 shows the calculated peak cylinder and knock timing pressure at varying engine intake pressure. The engine conditions for the calculation were 1500 RPM, spark ignition of 9 /BTDC, 1.0 bar intake pressure to simulated the WOT condition and an AFR of 14:1. The results showed that the knock timing advances as the intake pressure increases. This is clearly contributed to the fact that a higher intake pressure increases the in-cylinder effective compression ratio and compresses the unburned mixture harder that improves the fuel auto ignition conditions and leads to an earlier knock.

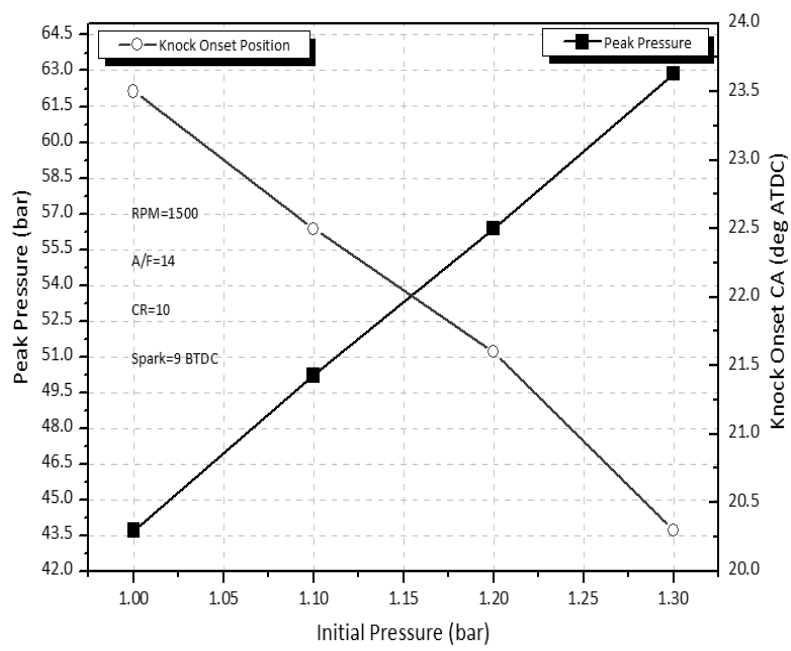

Figure 16: Calculated knock onset positions and peak pressures in respect of intake pressure

Figure 17 shows the calculated knock intensity and the combustion duration at varying intake pressure. Again, higher intake pressure results in higher knock intensity. The combustion duration calculated in the model is the duration after considering the auto ignition of the unburned mixture. It decreases as the intake pressure increases. This is because that the increased effective compression ratio due to intake pressure boost delivers stronger combustion, which pushes the unburned mixture ahead of the flame front harder. This leads to earlier and stronger auto ignitions. The enhanced auto ignition consumes more unburned mixture and reduces overall combustion duration. 


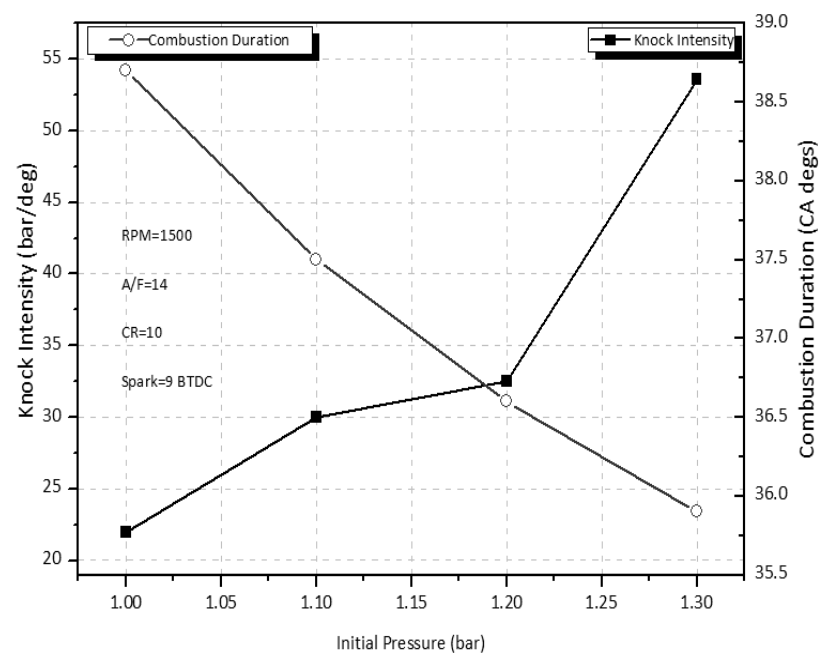

Figure 17: Calculated knock intensity and combustion durations in respect of intake pressure

Spark timing retardation is an efficient method to avoid the knock especially under boosted intake conditions. Figure 18 shows the simulated influences of the spark timing on the peak pressure and the knock positions at $1500 \mathrm{RPM}$, the $\mathrm{A} / \mathrm{F}$ ratio of $14: 1$ and WOT. It can be seen that as the ignition timing retards towards TDC position, the knock timing delays, too. When the spark timing is delayed to a certain level, no knock occurs and the combustion is safely in the non-knock region. The peak pressure decreases as the ignition timing is retarded, which is simply due to the weakened compression effect on the combustion with delayed ignition timing.

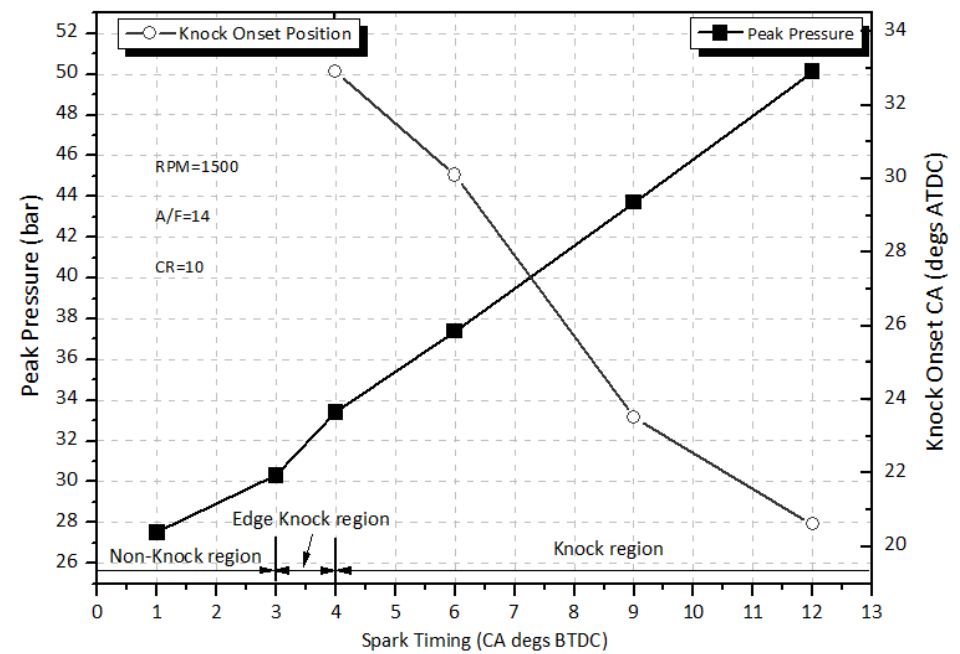

Figure 18: Calculated knock onset Positions and peak pressures in respect of spark timings

Figure 19 shows the simulated knock intensity and combustion duration at varying spark timings. It shows that as the spark timing delays, the knock intensity reduces. Again, this is contributed to the fact 
that the retardation of spark timing delays the combustion event and smoothes the strength of the flame propagation. The less compression and heat transfer from the delayed combustion reduces the strength of the knock and of course retards knock timing too. On the other side, the combustion duration increases as the spark timing retards. Again, this is mainly due to reduction in flame propagation strength.

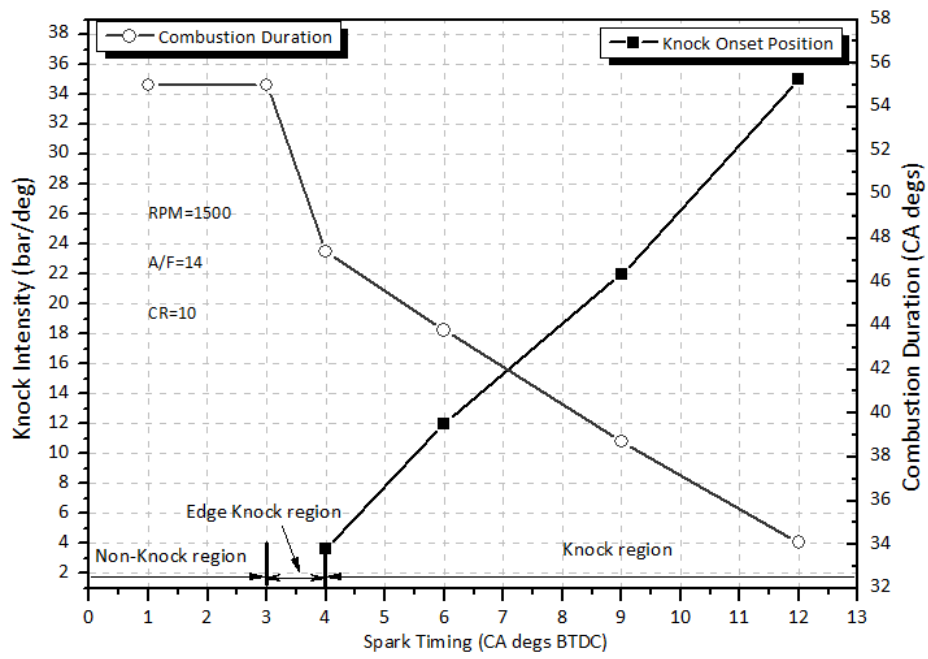

Figure 19: Calculated knock intensity and combustion durations in respect of sparking timings

\section{CONCLUSIONS}

The three-zone combustion model with reduced kinetics for SI engine knock simulation developed in this work can be generally summarized as:

- A zero-dimensional 3-zone SI engine combustion model incorporated with a reduced chemical kinetic mechanism has been developed.

- The Weibe function in the basic model has been corrected by the autoignition of the unburned mixture, which gives an improved mass fraction burned under knocking condition.

- The kinetics used in the model was initially developed for the autoignition of $\mathrm{HCCl}$ combustion. The reaction rate constants of the R6 and R18 in the chemical kinetics have been modified to improve the accuracy of autoignition prediction under SI combustion.

- A knock detection and process method has been developed to analyze the recorded cylinder pressure, identify the knocking cycles and determine the knock timing.

- The model has been validated against engine test data. Good agreements have been obtained.

- The model shows the potential in analyzing the relationship among ignition timing, knocks, and 
intake boost pressures

\section{LIST OF CAPTIONS FOR THE FIGURES}

Figure 1: Three-zone combustion chamber

Figure 2: Calculated knock position and peak pressure vs. Enhancing Factors in R6 and R18

Figure 3: Calculated knock intensity and combustion duration vs. Enhancing Factors in R6 and R18

Figure 4: The structure of the LUCKS program

Figure 5: Knock position on a typical measured pressure trace

Figure 6: Knock intensity .vs. knock positions of the identified knocking cycles

Figure 7: Calculated and measured in-cylinder pressure under non-knocking condition

Figure 8: Comparison of knock characteristics between calculated and measured data

Figure 9: Calculated in-cylinder pressure at varying AFR

Figure 10: Calculated and measured peak pressure at varying AFR

Figure 11: Calculated and measured knock onset position and knock intensity at varying AFR

Figure 12: Comparison of calculated and measured knock onset positions in respect of RPM

Figure 13: Comparison of calculated and measured peak pressures in respect of RPM

Figure 14: Comparison of calculated and measured knock intensity in respect of RPM

Figure 15: MFB with and without unburned mixture auto ignition

Figure 16: Calculated knock onset positions and peak pressures in respect of intake pressure

Figure 17: Calculated knock intensity and combustion durations in respect of intake pressure

Figure 18: Calculated knock onset Positions and peak pressures in respect of spark timings 
Figure 19: Calculated knock intensity and combustion durations in respect of sparking timings 


\section{Appendix 1}

CHEMKIN-formatted Chemical Kinetic Mechanism

$$
(\mathrm{k}=\mathrm{A} T * * \mathrm{~b} \exp (-\mathrm{E} / \mathrm{RT}))
$$

REACTIONS CONSIDERED

A $\quad$ b

1. $\mathrm{C} 7 \mathrm{H} 16+02\langle=>\mathrm{C} 7 \mathrm{H} 15+\mathrm{H} 02$

Reverse Arrhenius coefficients:

2. $\mathrm{C} 7 \mathrm{H} 15+02<=>\mathrm{C} 7 \mathrm{H} 1500$

Reverse Arrhenius coefficients:

3. $\mathrm{C} 7 \mathrm{H} 1500<=>\mathrm{C} 7 \mathrm{H} 1400 \mathrm{H}$

Reverse Arrhenius coefficients:

4. $\mathrm{C} 7 \mathrm{H} 140 \mathrm{H}+02<=>00 \mathrm{C} 7 \mathrm{H} 140 \mathrm{OH}$

Reverse Arrhenius coefficients:

5. $00 \mathrm{C} 7 \mathrm{H} 140 \mathrm{OH}=>0 \mathrm{C} 7 \mathrm{H} 130 \mathrm{OH}+\mathrm{OH}$

6. $\mathrm{C} 7 \mathrm{H} 16+\mathrm{OH}=>\mathrm{C} 7 \mathrm{H} 15+\mathrm{H} 20$

7. $\mathrm{C} 7 \mathrm{H} 15+02<=>\mathrm{C} 7 \mathrm{H} 14+\mathrm{H} 02$ Reverse Arrhenius coefficients:

8. $\mathrm{C} 7 \mathrm{H} 14+\mathrm{HO} 2+702=>7 \mathrm{CO}+7 \mathrm{H} 20+\mathrm{HO} 2$

9. $\mathrm{OC} 7 \mathrm{H} 130 \mathrm{OH}=>0 \mathrm{C} 7 \mathrm{H} 130+\mathrm{OH}$

10. $\mathrm{OC} 7 \mathrm{H} 130+02<=>0 \mathrm{C} 7 \mathrm{H} 120+\mathrm{H} 02$ Reverse Arrhenius coefficients:

11. $\mathrm{HO} 2+0 \mathrm{C} 7 \mathrm{H} 120+02=>\mathrm{H} 2 \mathrm{O} 2+\mathrm{OC} 7 \mathrm{H} 100+\mathrm{HO} 2$

12. $\mathrm{H} 02+0 \mathrm{C} 7 \mathrm{H} 100+502=>7 \mathrm{C} 0+5 \mathrm{H} 20+\mathrm{HO} 2$

13. $\mathrm{C} 8 \mathrm{H} 18+02<=>\mathrm{C} 8 \mathrm{H} 17+\mathrm{H} 02$ Reverse Arrhenius coefficients:

14. $\mathrm{C} 8 \mathrm{H} 17+02<=>\mathrm{C} 8 \mathrm{H} 1700$ Reverse Arrhenius coefficients:

15. $\mathrm{C} 8 \mathrm{H} 1700<=>\mathrm{C} 8 \mathrm{H} 160 \mathrm{OH}$ Reverse Arrhenius coefficients:

16. $\mathrm{C} 8 \mathrm{H} 160 \mathrm{OH}+02<=>00 \mathrm{C} 8 \mathrm{H} 1600 \mathrm{H}$ Reverse Arrhenius coefficients:

17. $00 \mathrm{C} 8 \mathrm{H} 1600 \mathrm{H}=>0 \mathrm{C} 8 \mathrm{H} 1500 \mathrm{H}+\mathrm{OH}$

18. $\mathrm{C} 8 \mathrm{H} 18+\mathrm{OH}=>\mathrm{C} 8 \mathrm{H} 17+\mathrm{H} 20$

19. $\mathrm{C} 8 \mathrm{H} 17+02<=>\mathrm{C} 8 \mathrm{H} 16+\mathrm{H} 02$ Reverse Arrhenius coefficients:

20. $\mathrm{C} 8 \mathrm{H} 16+\mathrm{HO} 2+802=>8 \mathrm{CO}+8 \mathrm{H} 20+\mathrm{HO} 2$

21. $\mathrm{OC} 8 \mathrm{H} 150 \mathrm{OH}=>0 \mathrm{C} 8 \mathrm{H} 150+0 \mathrm{H}$

22. 0 C 8 H150+02 $<=>0$ C8H140+H02 Reverse Arrhenius coefficients:

23. H02+0C 8 H140+02 $=>$ H2O2+OC 8 H120+H02
1. $00 \mathrm{E}+16 \quad 0.0 \quad 46000.0$

$\begin{array}{lll}1.00 \mathrm{E}+12 & 0.0 & 0.0\end{array}$

1. $00 \mathrm{E}+12 \quad 0.0 \quad 0.0$

$2.51 \mathrm{E}+13 \quad 0.0 \quad 27400.0$

$\begin{array}{lll}1.51 \mathrm{E}+11 & 0.0 & 19000.0\end{array}$

1. $00 \mathrm{E}+11 \quad 0.0 \quad 11000.0$

$\begin{array}{lll}3.16 \mathrm{E}+11 & 0.0 & 0.0\end{array}$

$2.51 \mathrm{E}+13 \quad 0.0 \quad 27400.0$

8. $91 \mathrm{E}+10 \quad 0.0 \quad 17000.0$

1. $00 \mathrm{E}+13 \quad 0.0 \quad 3000.0$

3. $16 \mathrm{E}+11 \quad 0.0 \quad 6000.0$

3. $16 \mathrm{E}+11 \quad 0.0 \quad 19500.0$

3. $16 \mathrm{E}+13 \quad 0.0 \quad 10000.0$

3. $98 \mathrm{E}+15 \quad 0.0 \quad 43000.0$

$3.16 \mathrm{E}+11 \quad 0.0 \quad 6000.0$

3. $16 \mathrm{E}+11 \quad 0.0 \quad 19500.0$

3. $16 \mathrm{E}+13 \quad 0.0 \quad 10000.0$

3. $16 \mathrm{E}+13 \quad 0.0 \quad 10000.0$

1. $00 \mathrm{E}+16 \quad 0.0 \quad 46000.0$

$\begin{array}{lll}1.00 \mathrm{E}+12 & 0.0 & 0.0\end{array}$

1. $00 \mathrm{E}+12 \quad 0.0 \quad 0.0$

$2.51 \mathrm{E}+13 \quad 0.0 \quad 27400.0$

1. $14 \mathrm{E}+11 \quad 0.0 \quad 22400.0$

1. $00 \mathrm{E}+11 \quad 0.0 \quad 11000.0$

$\begin{array}{lll}3.16 \mathrm{E}+11 & 0.0 & 0.0\end{array}$

$2.51 \mathrm{E}+13 \quad 0.0 \quad 27400.0$

8. $91 \mathrm{E}+10 \quad 0.0 \quad 17000.0$

1. $00 \mathrm{E}+13 \quad 0.0 \quad 3000.0$

3. $16 \mathrm{E}+11 \quad 0.0 \quad 6000.0$

3. $16 \mathrm{E}+11 \quad 0.0 \quad 19500.0$

2. $00 \mathrm{E}+13 \quad 0.0 \quad 10000.0$

$3.98 \mathrm{E}+15 \quad 0.0 \quad 43000.0$

$3.16 \mathrm{E}+11 \quad 0.0 \quad 6000.0$

$\begin{array}{lll}3.16 \mathrm{E}+11 & 0.0 & 19500.0\end{array}$

$\begin{array}{lll}1.58 \mathrm{E}+13 & 0.0 & 10000.0\end{array}$ 
24. $\mathrm{HO} 2+0 \mathrm{C} 8 \mathrm{H} 120+602=>8 \mathrm{CO}+6 \mathrm{H} 20+\mathrm{HO} 2$

1. $58 \mathrm{E}+13$

0. 0 10000. 0

25. $\mathrm{C} 8 \mathrm{H} 18+\mathrm{C} 7 \mathrm{H} 15<=>\mathrm{C} 7 \mathrm{H} 16+\mathrm{C} 8 \mathrm{H} 17$

5. $01 \mathrm{E}+12$

0. 0

0.0

26. $\mathrm{OH}+\mathrm{H} 2=\mathrm{H}+\mathrm{H} 2 \mathrm{O}$

2. $14 \mathrm{E}+08$

1. 5

3449. 0

27. $\mathrm{O}+\mathrm{OH}=\mathrm{O} 2+\mathrm{H}$

2. $02 \mathrm{E}+14$

$-0.4$

0.0

28. $0+\mathrm{H} 2=\mathrm{OH}+\mathrm{H}$

5. $06 \mathrm{E}+04$

2. 7

6290. 0

29. $\mathrm{H}+02(+\mathrm{M})=\mathrm{H} 02(+\mathrm{M})$

4. $52 \mathrm{E}+13$

0.0

0.0

Declared duplicate reaction...

Low pressure limit: $0.10500 \mathrm{E}+20-0.12570 \mathrm{E}+01 \quad 0.00000 \mathrm{E}+00$

$\begin{array}{lll}\text { H2O } & \text { Enhanced by } & 0.000 \mathrm{E}+00 \\ \mathrm{H} 2 & \text { Enhanced by } & 0.000 \mathrm{E}+00 \\ \mathrm{H} 20 & \text { Enhanced by } & 0.000 \mathrm{E}+00 \\ \text { H2 } & \text { Enhanced by } & 0.000 \mathrm{E}+00 \\ \text { N2 } & \text { Enhanced by } & 0.000 \mathrm{E}+00\end{array}$

30. $\mathrm{H}+\mathrm{O} 2(+\mathrm{N} 2)=\mathrm{H} 02(+\mathrm{N} 2)$

4. $52 \mathrm{E}+13$

0.0

0.0

Declared duplicate reaction...

Low pressure limit: $0.20300 \mathrm{E}+21-0.15900 \mathrm{E}+01 \quad 0.00000 \mathrm{E}+00$

31. $\mathrm{H}+02(+\mathrm{H} 2)=\mathrm{H} 02(+\mathrm{H} 2)$

4. $52 \mathrm{E}+13$

0.0

0.0

Declared duplicate reaction...

Low pressure limit: $0.15200 \mathrm{E}+20-0.11330 \mathrm{E}+01 \quad 0.00000 \mathrm{E}+00$

32. $\mathrm{H}+02(+\mathrm{H} 20)=\mathrm{H} 02(+\mathrm{H} 20)$

4. $52 \mathrm{E}+13$

0.0

0.0

Declared duplicate reaction...

Low pressure limit: $0.21000 \mathrm{E}+24-0.24370 \mathrm{E}+01 \quad 0.00000 \mathrm{E}+00$

33. $\mathrm{OH}+\mathrm{HO} 2=\mathrm{H} 2 \mathrm{O}+\mathrm{O} 2$

2. $13 \mathrm{E}+28-4.8$

3500. 0

Declared duplicate reaction...

34. $\mathrm{OH}+\mathrm{HO} 2=\mathrm{H} 2 \mathrm{O}+02$

9. $10 \mathrm{E}+14$

0. $0 \quad 10964.0$

Declared duplicate reaction...

35. $\mathrm{H}+\mathrm{HO} 2=\mathrm{OH}+\mathrm{OH}$

1. $50 \mathrm{E}+14$

0.0

1000. 0

36. $\mathrm{H}+\mathrm{H} 02=\mathrm{H} 2+02$

8. $45 \mathrm{E}+11$

0.7

1241.0

37. $\mathrm{H}+\mathrm{H} 02=0+\mathrm{H} 20$

3. $01 \mathrm{E}+13$

0.0

1721. 0

38. $0+\mathrm{HO} 2=02+\mathrm{OH}$

3. $25 \mathrm{E}+13$

0.0

0.0

39. $\mathrm{OH}+\mathrm{OH}=\mathrm{O}+\mathrm{H} 20$

3. $57 \mathrm{E}+04$

2. 4

$-2112.0$

40. $\mathrm{H}+\mathrm{H}+\mathrm{M}=\mathrm{H} 2+\mathrm{M}$

1. $00 \mathrm{E}+18$

$-1.0$

0.0

H2O

Enhanced by

0. $000 \mathrm{E}+00$

H2

Enhanced by

0. $000 \mathrm{E}+00$

41. $\mathrm{H}+\mathrm{H}+\mathrm{H} 2=\mathrm{H} 2+\mathrm{H} 2$

9. $20 \mathrm{E}+16$

$-0.6$

0. 0

42. $\mathrm{H}+\mathrm{H}+\mathrm{H} 2 \mathrm{O}=\mathrm{H} 2+\mathrm{H} 2 \mathrm{O}$

6. $00 \mathrm{E}+19$

$-1.2$

0.0

43. $\mathrm{H}+\mathrm{OH}+\mathrm{M}=\mathrm{H} 2 \mathrm{O}+\mathrm{M}$

2. $21 \mathrm{E}+22$

$-2.0$

0.0

Enhanced by

6. $400 \mathrm{E}+00$

44. $\mathrm{H}+\mathrm{O}+\mathrm{M}=\mathrm{OH}+\mathrm{M}$

Enhanced by

4. $71 \mathrm{E}+18$

$-1.0$

0. 0

45. $0+0+\mathrm{M}=02+\mathrm{M}$

6. $400 \mathrm{E}+00$

46. $\mathrm{H} 02+\mathrm{HO} 2=>\mathrm{H} 202+02$

1. $89 \mathrm{E}+13$

$0.0-1788.0$

47. $\mathrm{H} 2 \mathrm{O} 2+\mathrm{M}=>\mathrm{OH}+\mathrm{OH}+\mathrm{M}$

2. $00 \mathrm{E}+10$

$0.0 \quad 5000.0$

48. $\mathrm{H} 2 \mathrm{O} 2+\mathrm{H}=\mathrm{H} 02+\mathrm{H} 2$

1. $00 \mathrm{E}+16$

0. $0 \quad 48000.0$

1. $98 \mathrm{E}+06$

2. 0

2435. 0 

49. $\mathrm{H} 2 \mathrm{O} 2+\mathrm{H}=\mathrm{OH}+\mathrm{H} 2 \mathrm{O}$
3. $07 \mathrm{E}+13$
0. 0
4217. 0
50. $\mathrm{H} 2 \mathrm{O} 2+\mathrm{O}=\mathrm{OH}+\mathrm{HO} 2$
9. $55 \mathrm{E}+06$
2. 0
3970. 0
51. $\mathrm{H} 2 \mathrm{O} 2+\mathrm{OH}=\mathrm{H} 2 \mathrm{O}+\mathrm{H} 02$
2. $40 \mathrm{E}+00$
4. $0 \quad-2162.0$
52. $0+\mathrm{CO}(+\mathrm{M})<=>\mathrm{CO} 2(+\mathrm{M})$
1. $80 \mathrm{E}+10$
0.0
2385. 0
Low pressure limit: $0.60200 \mathrm{E}+15 \quad 0.00000 \mathrm{E}+00 \quad 0.30000 \mathrm{E}+04$

H2

Enhanced by

2. $000 \mathrm{E}+00$

02

Enhanced by

6. $000 \mathrm{E}+00$

$\mathrm{H} 20$

Enhanced by

6. $000 \mathrm{E}+00$

$\mathrm{CO}$

Enhanced by

1. $500 \mathrm{E}+00$

C02

Enhanced by

3. $500 \mathrm{E}+00$

AR

Enhanced by

5. $000 \mathrm{E}-01$

53. $02+\mathrm{C} 0<=>0+\mathrm{C} 02$

2. $50 \mathrm{E}+12$

0. $0 \quad 47800.0$

54. $\mathrm{CO}+\mathrm{OH}<=>\mathrm{CO} 2+\mathrm{H}$

4. $76 \mathrm{E}+07$

1. 2

70. 0

55. $\mathrm{HO} 2+\mathrm{CO}<=>\mathrm{OH}+\mathrm{CO} 2$

4. $76 \mathrm{E}+13$

0. 0 23600. 0

NOTE: A units mole-cm-sec-K, E units cal/mole

\section{REFERRENCE}

Curran, H. J., Gaffuri, P., Pitz, W. J., and Westbrook, C. K. (2002), 'A Comprehensive Modeling Study of iso-Octane Oxidation,' Combust. Flame 129(3), 253-280.

${ }^{2}$ Curran, H.J., Gaffuri, P., Pitz, W.J. and Westbrook, C.K. (1998): "A Comprehensive 
Modeling Study of n-Heptane Oxidation," Combust. Flame 114, 149-177.

${ }^{3}$ Agosta, A., Cernansky, N.P., Miller, D.L., Faravelli, T. and Ranzi, E. (2004), "Reference Components of Jet Fuel: Kinetic Modeling and Experimental Results," Exp. Therm. Fluid. Sci. 28(7), 701-708.

${ }^{4} \mathrm{Li}$, H., Miller, D. L. and Cernansky, N. P., (1992), 'A Study on the Application of a Reduced Chemical Reaction Model to Motored Engines for Heat Release Prediction,' SAE Paper No. 922328, SAE Trans. 101, Section 3, 2021-2034.

5 Tanaka, S., Ayala, F., Keck, C. J. (2003a) 'A reduced chemical kinetic model for HCCI combustion of primary reference fuels in a rapid compression machine'. Sloan Automotive Laboratory, Massachusetts Institute of Technology, Cambridge, MA 02139.

${ }^{6}$ Tanaka, S., Ayala, F., Keck, C. J. and Heywood, J. B. (2003b), 'Two-stage ignition in $\mathrm{HCCl}$ combustion and $\mathrm{HCCl}$ control by fuels and additives'. Combustion and Flame, Volume 132, Issues 1-2, January 2003, Pages 219-239

7. Halstead, M. P., Kirsch, L. J., Prothero, A. and Quinn, C. P. (1975), 'A Mathematical Model for Hydrocarbon Autoignition at High Pressure,' Proc. Roy. Soc. A346, 515-538.

8 Zheng, J., Miller, D.L. and Cernansky, N.P. (2004), "A Global Reaction Model for the $\mathrm{HCCl}$ Combustion Process," Poster No. 4F1-18, 30th Intl. Symp. On Combust. 
9 Zheng J. (2005), A Study of Homogeneous Ignition and Combustion Processes in $\mathrm{Cl}$, SI, and $\mathrm{HCCl}$ Engine Systems, PHD thesis, Drexel University'

${ }^{10}$ Oran, E, Boris, J (1991),Numerical Approaches to combustion Modeling

11 Kaario, O, Larmi, M and Tanner, F (2002), 'Comparing Single-Step and Multi-Step Chemistry Using the Laminar and Turbulent Characteristic Time Combustion Model in Two Diesel Engines', SAE 2002-01-1749.

${ }^{12}$ Liu, J, Gong, J and Cai, L. (2006) 'Multi-Dimensional Simulation of Air/Fuel Premixing and Stratified Combustion in a Gasoline Direct Injection Engine with Combustion Chamber Bowl Offset', SAE 2006-32-0006

${ }^{13}$ Blunsdon, C. A. and Dent, J.C. 'The Simulation of Autoignition and Knock in a Spark Ignition Engine With Disk Geometry', SAE 940524

${ }^{14}$ Kong, S, Han, Z, and Reitz, R, 1995, 'The Development and Application of a Diesel Ignition and Combustion Model for Multidimensional Engine Simulations' SAE 950278

${ }^{15}$ Eckert, P, Kong, S and Reits, R, (2003), 'Modeling Autoignition and Engine Knock Under Spark Ignition Conditions', SAE 2003-01-0011

${ }^{16}$ Ferguson, C. R, (1986), Internal Combustion engines 
17 Ferguson, C. R. and Kirkpatrick, A. T. Internal Combustion Engines: Applied Thermodynamics, John Wiley \& Sons, Inc. (2001). p.369.

18 Najt, P. M., (1987), 'Evaluating Threshold Knock With a Semi-Empirical Model--Initial Results', SAE 872149

19 Mose, E, Yarin, A and Yoseph, B, (1995), 'On Knocking Prediction in Spark Ignition Engines', Combustion and Flame 101: 239-261

20 Noda T., Kazuya H. (2004) 'Development of Transient Knock Prediction Technique By Using a Zero-Dimensional Knocking Simulation With Chemical Kinetics', SAE 2004-01-0618.

${ }^{21}$ Hajireza, S., Mauss, F., Sunden, B. A. (1997), 'Investigation of End-Gas Temperature and Pressure Increases in Gasoline Engines and Relevance for Knock Occurrence', SAE971671.

${ }^{22}$ Hajireza, S., Mauss, F., Sunden, B. A. (1999), 'Three-Zone Model for Investigation of Gas Behavior in the Combustion Chamber of SI Engines in Relation to Knock', SAE 1999-01-0219

${ }^{23}$ Gordon, S. and McBride, B. J. (1994), 'Computer Program for Calculation of Complex Chemical Equilibrium Compositions and Applications I. Analysis'. NASA RP 1311

${ }^{24}$ Woschni, G. (1967), 'A Universally Applicable Equation for the Instantaneous Heat 
Transfer Coefficient in the Internal Combustion Engine', SAE Paper No. 670931.

${ }^{25}$ Heywood, J.B. (1988), Internal Combustion Engine Fundamentals.

${ }^{26} \mathrm{Li}, \mathrm{H}$. , Srinivasa K. Prabhu (1994) 'Autoignition Chemistry Studies on Primary Reference Fuels in a Motored Engine', SAE 942062.

${ }^{27}$ Westbrook C. K., H.J. Curran, W.J. Pitz., C.V. Callahan, F.L. Dryer. (1998), 'Oxidation of Automotive Primary Reference Fuels at Elevated Pressures'. Twenty-Seventh International Conference on Combustion.

28 Westbrook C. K. (2000), 'Chemical Kinetics of Hydrocarbon Ignition in Practical Combustion Systems'. 28th International Symposium on Combustion.

29 Reynolds W.C. (1986), 'The element potential method for chemical equilibrium analysis: implementation in the interactive program STANJAN-III, Technical report'. Department of Mechanical Engineering, Stanford University

30 Arrigoni. V, Cornetti G. M. (1974). 'High Speed Knock in S.I. Engines', SAE 741056.

31 Swarts A., Yates, A., Viljoen, C. (2004). 'Standard Knock Intensity Revisited: Atypical Burn Rate Characteristics Identified in the Cfr Octane Rating Engine', SAE 2004-01-1850. 
32 Swarts A., Yates, A., Viljoen, C. (2004). 'Standard Knock Intensity Revisited: Atypical Burn Rate Characteristics Identified in the CFR Octane Rating Engine', SAE 2004-01-1850.

${ }^{33}$ Takagi, Y., Itoh, T. (1988), 'An Analytical Study on Knocking Heat Release and Its Control in a Spark Ignition Engine', SAE 880196

34 Noda T., Kazuya H. (2004) 'Development of Transient Knock Prediction Technique By Using a Zero-Dimensional Knocking Simulation With Chemical Kinetics', SAE 2004-01-0618. 